\title{
Supporting Factor Analysis in Health Promotion Hospital in Muhamadiyah Hospital, Lamongan
}

\section{Badra Al-Aufa ${ }^{1}$ and Ratu Ayu Dewi Sartika²}

${ }^{1}$ Hospital Administration Department, Vocational Program of Universitas Indonesia, Depok, Indonesia

${ }^{2}$ Public Health Faculty, Universitas Indonesia, Depok, Indonesia

\section{Abstract}

Implementation of health promotion hospital is deemed not quite good enough. Although, health promotion has been implemented in Lamongan Muhammadiyah Hospital, there are still problems that interfere the implementation. This study aimed to describe the factors that support the implementation of health promotion hospital in Lamongan Muhammadiyah Hospital. This research uses a qualitative method.

Corresponding Author: Badra Al-Aufa badraalaufa@gmail.com

Received: 8 June 2018 Accepted: 17 July 2018 Published: 8 August 2018

Publishing services provided by Knowledge $\mathrm{E}$

(c) Badra Al-Aufa and Ratu Ayu Dewi Sartika. This article is distributed under the terms of the Creative Commons

Attribution License, which permits unrestricted use and redistribution provided that the original author and source are credited.

Selection and Peer-review under the responsibility of the $2 n d$ ICVHE Conference Committee. Factors that influence an implementation of health promotion hospital developed by the Ministry of Health of Indonesia have been used as the conceptual framework. That concept says that the commitment of management, the existence of special unit and worker, HPH training, facilities and tools and fund influence an implementation of $\mathrm{HPH}$. Interviewees have been selected using purposive sampling and snowball sampling method. Interviewees in this research are the Directors of hospital, Head and Members of HPH unit and patients. Sources of data are divided into two parts. The first part is the primary data that are the result of interview, document analysis, focus group discussion and observation, and the second part is the secondary data that are the documents that needed to answer the purpose of this study. All of the directors show that they have a commitment in the implementation of HPH. An HPH Team has been created. Hospital still do not have a special health promotion worker. HPH training is still rarely implemented. Hospitals have a good and enough facilities and tools for implementing health promotion. Funding of health promotion has been arranged by every department in the hospital.

Keywords: supporting factors, health promotion hospital, qualitative approach

\section{Introduction}

Hospital as one of health service institution in secondary level has a duty to give a personal plenary health service, which include promotive, preventive, curative, and rehabilitative (SKN and UU RS). However, fact shows that health promotion in hospital 
this time do not show any positive result. Hospital also more concern in curative and rehabilitative aspect and neglect promotive and preventive aspect.

World Health Organization (WHO) in 1970-1980 already developed Hospital Health Promotion (HPH) which has been implemented in late 1980. In national level, Kementerian Kesehatan Republik Indonesia already made various policy about health promotion in hospital such as health promotion standard in hospital in 2012 and technical guidelines of health promotion in hospital implementation in 2012.

Rifaskes' data in 2011 showed that only $52 \%$ of government hospitals do elucidation, $15.4 \%$ do Puskesmas (primer health services) supervision, and $73.6 \%$ do other promotional things such as assembly of health related poster or banner. In other factor that have strong correlation with health promotion, this data described that only $43.3 \%$ of government hospitals that have special unit which manage PKRS, $44.4 \%$ hospitals which have written policy about PKRS, 38.8\% which have special budget for PKRS, and $31.8 \%$ hospitals do not have properties to do health promotion.

Health promotion implementation in hospital depends on some factors such as, commitment from health services management, sources availability, communication system, action plan, evaluation, education, research, sustainability, and integrated network among other health services (WHO Regional Office for Europe, 2007). According to technical guidelines of health promotion in hospital that made by Kementerian Kesehatan, method, media, and source are influence factors.

This research conducted in Muhamadiyah hospital in Lamongan. This hospital has 2012 plenary accreditation version. However, prior study in this hospital showed that there were many problem related to health promotion implementation such as unplanned program and lack of coordination between PKRS unit and hospital crew. The other objection of this research is to describe supporting factor of health promotion in hospital especially in Muhamadiyah hospital in Lamongan.

\section{Methods}

Qualitative method has been chosen for this research's method. Theory which is used in this research based on the concept that was developed by Kementerian Kesehatan about health promotion influenced factors, PKRS training, tools and properties, and budget.

Purposive and snowball sampling method have been chosen to choose informants. Researcher implemented triangulation data method to minimalize bias. Primer data for this research have been collected by interview, document study, and observation, 
while the secondary data collected from the other documents. Data source based on informant chosen and data collection methods is explained in Table 1. According to data collection method, this research's instruments are interview, FGD, document analysis and observation manuals. Content analysis method has been chosen to analyze the data on this research. In this method, researcher collected and analyzed the content from word, mean, picture, symbol, idea, theme, message or other communication methods. Data was analyzed manually with no software help.

\section{Result}

\subsection{Informant characteristic}

This research divided informants into 3 categories, Table 1 explained about PKRS member informant. Tables 2 and 3 described about nonmember PKRS hospital crew and citizen who already serviced by RS Muhamadiyah Lamongan health promotion program, respectively.

\subsection{Director and management commitment}

All informants state that director and management Muhamadiyah hospital in Lamongan have a commitment on PKRS implementation in this hospital. This support was showed by the preparation of operational plans. PKRS team assignations, guidelines making, tools and properties provision, and cost's compliance were the other support that gave by the direction and management.

"Really commit. It showed by the well structure Binkesmas that lead by PKRS team that consist of people from various field." (c Informant)

"I feel there are some commitments for these things. Seen from some of the things we do both inside and outside, such as radio broadcasts." (Q Informant)

"In my opinion it is already good enough. For example, in my case, even though I already release from that hospital, but they keep informed me once in three month."(G Informant) 


\subsection{Special unit and crew for health promotion}

Muhamadiyah hospital have no special crew for health promotion that comply Permenkes about 2012 PKRS Implementation Guidelines. Other informant also state that this hospital need the availability of health promotion crew.

"It is needed. Special crew will have full concentration in his/him field. Both outpatient and inpatient units need this special crew. Structural person should not be this special crew due their workload. Doctor, nurse, marketer, nutritionist, dentist, and pharmacist should be the one who become special crew" (A Informant)

PKRS special unit was straight under Director of the hospital and being made as a team which contains some units. PKRS structure could be seen in picture 1. PKRS team leader is professional who have a duty and right to leads and runs PKRS programs. At this time, PKRS team leader is a doctor who also a leader of Bimkesmas.

Informant stated that the structure is already well built. This structure involved some work units or hospital units that keep in contact with citizen directly. However, this structure also has a negative point. In this structure, PKRS crews were chosen from other division crews, this made PKRS crews often think that PKRS are only their side job. Team tight schedule also made coordination among crew hard to build. Some informants suggested that a special unit has to be set up specifically to handle PKRS activities.

"effective enough, But it still need some coordinator not the executor." (L Informant)

"Not Focus, people often thinks it as their side job."(N Informant)

"Still not focus enough, people always think it not their main job."(M Informant)

Several other informants suggested to add some additional charge of human resources specifically to assist the chairman to perform administrative activities such as planning team coordination meetings, preparation of reports and documentation activities.

"Giving specific person, so PKRS can develop more."(M Informant)

"Need some technical support to help the chairman remind, encourage coordination so that the report can be arranged." (L Informant) 


\subsection{Training related to health promotion}

Training related to health promotion hospitals last done in 2013. There are four people who followed the training, which are two doctors and two nurses. Training materials related to training to be educators. The four persons who have been trained educators are expected to share their experiences, knowledge, and skills to other officers in the Muhammadiyah hospital, Lamongan in activities like in House Training, so that required retraining related to the upgrading of the implementation of health promotion.

"there are nurses and doctors." (D and N Informants)

"Educator training." (A,D,L,N,Q,T Informants)

"hospitals rarely done some training about PKRS or educator, informations about training are quite rare." (L Informant)

\subsection{Tools and properties}

Based on in-depth interviews, observation and document review, PKRS team does not have a specific inventory items. During this time, the equipment used is owned by the Secretariat of the RS Muhammadiyah Lamongan. The equipment is often used in the PKRS are laptops, LCD, sound system, TV, camera, flipchart. Besides media used in PKRS activities include leaflets, banners, radio broadcasts, as well as articles on the web hospitals. PKRS in organizing activities with the target group, for example, an extension, then used a room or hall at the hospital.

"yes, we have LCD and sound system attached with microphone and others. There are $C D$, videotoper, and others too. Leaflet and others also present there." (C Informant)

"Television, radio by prameswara, poster, leaflet in every rooms and LDC. There are some education leaflet in every patients' rooms." (A Informant)

"Is still constrained about the room. For example in the form of poly activities. There is no place quite freely to look at one point. In addition we also do not have a specific office." (A Informant)

As for the condition of the equipment used in the PKRS activities are still good and have sufficient quantity. Provision and maintenance of facilities and infrastructures 
were done by the Administration and the Secretariat. So far, PKRS do not encountered with significant problems in the procurement and maintenance of the properties. Problem associated with infrastructure is the lack of dedicated space for PKRS team's office. During this time, the PKRS team using the other empty room to do coordination.

\subsection{Budgeting}

In planning the work program, drawn up plans or budget are required for each activity. Budget funds are designed on each unit or portion included in PKRS team. Sources of funding on each activity PKRS derived from APB (Anggaran Pendapatan dan Belanja) RS Muhammadiyah Lamongan. According entire informants, hospital already provided sufficient funds for the entire implementation of the activities PKRS.

"From us, we set aside for organizing. This budget set aside from promotion budget other than its own budget."(E Informant)

"there are activity budget. From main budget or APB."(L Informant)

"there are no certain budget. But there are some budget for individual activity when needed." (N Informant)

Related to the special allowance, up to now there is no special allowance granted to PKRS team. That is because the task as PKRS team is part of the task that it should be done. Most informants consider this to be a problem. According entire informant, the commitment of directors in terms of funding PKRS activity has been very good and there was no problem in the implementation of the activities related to the financing PKRS in Lamongan Muhammadiyah Hospital.

\subsection{Discussion}

In digging up information related to a research question to informants, some informants often do not understand correctly about the concept of health promotion hospitals. Therefore, some answers from the informants are too wide, sliced with the other topics such as the quality of the hospital. Another limitation is the lack of knowledge rather than organizing PKRS every relevant staff in the hospital is limited between one and the other answers may differ in stating one thing. The study also focuses on a comprehensive picture of the general and related to factors that affect the implementation of health promotion so there was noted every detail in describing these factors. 
Director and management have been committed in PKRS implementation. Special units directly under the Director of the hospital and consists of several units or parts, so PKRS activities carried out by hospital personnel from various fields such as doctors, nurses, midwives, nutritionists, and clinical pharmacy officer. No special officer of health promotion. PKRS specialized training is still very rare. There some infrastructure equipment in conducting PKRS. Funding in the operation designed PKRS of each unit or portion included in PKRS team.

The success of health promotion implementation in hospitals is due to the support from the owners and management of the hospital. In another study stated that the promotion and health prevention is not a major priority for the hospital management. This can be caused by lack of understanding of the concept of leadership related to hospital health promotion. In addition, other reason of the lack of leadership enthusiastic in implementing health promotion hospitals is the lack of developing health promotion background [6]

Muhamadiyah hospital have no specific human resource who comply with Peraturan Menteri Kesehatan about specific human resource [5]. WHO also stated, capacity building are one of the most important steps to promote health promotion in hospital, include professional education for the staff (Integrating health promotion into hospitals and health services Concept, framework and organization).

Muhammadiyah hospital conducted some training related to health promotion in hospital in 2013. One of the important components in health promotion in hospital implementation are staff engagement and their ability. Research shows that there are positive relation between the success of stop smoking program between trained and untrained nurses [2].

Other components that crucial for program succession are tools and properties. Even though PKRS in Muhammadiyah hospital have no tools and properties by its own, Muhammadiyah hospital secretariat already provide the good condition tools and properties for the program. In a study revealed that more than $40 \%$ of hospitals in rural areas could not carry out some health promotion programs because of limited hospital resources (MS, 1993).

In budgeting area, it has been found that budgeting/funding for PKRS activity are good enough and have no problem related to it. Financial investment have been one component in conducting health promotion. Research in one of the metropolitan area of Belo Horizonte, Brazil mentioned that there are still challenges in implementing health promotion such as limited financial and inter-sectoral cooperation [9]. 


\section{Conclusions and Suggestions}

Support factor conditions in PKRS implementation in Muhammadiyah hospital in Lamongan are good enough at several things such as, commitment, tools and properties, and budgeting/funding. However, there are several problems in specific unit formation, specialized personal selection, and staff training.

Muhammadiyah hospital management is expected to make adjustments in SK Director RS associated with a special staff qualifications of PKRS with regulations made by the Ministry of Health so that there are similarities qualifying special health promotion officer. Training related to health promotion to the hospital staff shall be done, so that all hospital staff has the capability to carry out health promotion properly.

\section{References}

[1] Dietscher, C. J. (2015, JUNE 15). Health Promoting Hospitals. Retrieved from www.oxfordbibliographies.com: http://www.oxfordbibliographies.com/ view/document/obo-9780199756797/obo-9780199756797-0131.xml\#obo9780199756797-0131-div1-0001

[2] Evidence-based Health Promotion in Clinical Settings. (2008, September 19). Retrieved from www.ohpe.ca: http://www.ohpe.ca/node/9975

[3] Groene, O. S. (2005). Health promotion in hospitals-a strategy to improve quality in health care. European Journal of Public Health, 6-8.

[4] Kahan, B., \& Goodstadt, M. (1999). Continuous Quality Improvement and Health promotion: can CQI lead to better outcomes? Health promotion international, 83-91.

[5] Kementerian Kesehatan. (2012). Peraturan Menteri Kesehaton Republik Indonesia Nomor 004 Tahun 2012 tentang Petunjuk Teknis Promosi Kesehatan Rumah Sakit. Retrieved from www.hukor.depkes.go.id: http://www.hukor.depkes.go.id/uploads/produk_hukum/PMK\{\%\}20No. $\{\%$ 20004\{\%\}20ttg\{\%\}20JUKNIS $\{\%$ \}20Promosi\{\%\}20Kesehatan\{\%\}20RS.pdf

[6] Lee, B., Chen, M., Powell, M., \& MC, C. (2013). Organisational Change to Health Promoting Hospitals: A Review of the Literature. Springer Science Review, 13-23.

[7] Manurung, S., Suriah, \& Ngatimin, M. (2015). Implementation of Health Promotion Program in General Hospital of Labuang Baji Makassar, 2015. International Journal of Sciences: Basic and Applied Research, 80-87.

[8] National Health Service. (2013). www.institute.nhs.uk. Retrieved from Prevention is better than cure: http://www.institute.nhs.uk/building_capability/ 
technology_and_product_innovation/prevention_is_better_than_cure.html

[9] Silva, K., de Sena, R., Belga, S., Silva, P., \& Rodrigues, A. (2014). Health promotion: challenges revealed in succesfull practices. Rev Saúde Pública, 76-85.

[10] Yaghoubi, M., \& Javadi, M. (2013). Health promoting Hospitals in Iran: How it is. Education Health Promotion Journal. 